\title{
Interactive Foresight Simulation
}

\section{Hansen, Mette Sanne; Rasmussen, Lauge Baungaard; Jacobsen, Peter}

\section{Published in:}

Technological Forecasting and Social Change

Link to article, DOI:

10.1016/j.techfore.2015.10.011

Publication date:

2016

Document Version

Peer reviewed version

Link back to DTU Orbit

Citation (APA):

Hansen, M. S., Rasmussen, L. B., \& Jacobsen, P. (2016). Interactive Foresight Simulation. Technological Forecasting and Social Change, 103, 214-227. https://doi.org/10.1016/j.techfore.2015.10.011

\section{General rights}

Copyright and moral rights for the publications made accessible in the public portal are retained by the authors and/or other copyright owners and it is a condition of accessing publications that users recognise and abide by the legal requirements associated with these rights.

- Users may download and print one copy of any publication from the public portal for the purpose of private study or research.

- You may not further distribute the material or use it for any profit-making activity or commercial gain

- You may freely distribute the URL identifying the publication in the public portal

If you believe that this document breaches copyright please contact us providing details, and we will remove access to the work immediately and investigate your claim. 


\title{
INTERACTIVE FORESIGHT SIMULATION
}

\author{
METTE SANNE HANSEN \\ DTU Management Engineering, Technical University of Denmark \\ Diplomvej Bygning 372 \\ Kgs. Lyngby, 2800, Denmark \\ mesa@dtu.dk \\ LAUGE BAUNGAARD RASMUSSEN \\ DTU Management Engineering, Technical University of Denmark \\ Diplomvej Bygning 372 \\ Kgs. Lyngby, 2800, Denmark \\ lras@dtu.dk \\ PETER JACOBSEN \\ DTU Management Engineering, Technical University of Denmark \\ Produktionstorvet Bygning 424 \\ Kgs. Lyngby, 2800, Denmark \\ peja@dtu.dk
}

\begin{abstract}
The Combined Simulation Approach (CSA) is a way to evaluate risks and address potential unforeseen problems in a more interactive way than what is often observed in practice in companies or sectors. The approach is based on a combination of scenario analysis and discrete-event computer simulation with which the strategies can be continuously developed. The contribution of this paper is to narrow the knowledge gap between strategic, tactical and operational levels of an organisation. The paper demonstrates how it is possible to work proactively with both the breadth and depth of strategies using a Danish knowledge intensive company as an example.
\end{abstract}

Keywords: Narrative simulation, numerical simulation, foresight, scenario building, strategy, backsourcing

\section{Introduction}

Future studies can be based on either forecast or foresight methodologies. Forecasting is the attempt to estimate or predict future occurrences [111-118]. In contrast, foresight studies do not attempt to predict future events, but to imagine and analyze the impacts of several possible futures [1-4, 37, 57-60]. This paper focuses on foresight, especially how foresight studies can benefit from a combined narrative and numerical simulation approach, as well as the potential pitfalls of such an approach. The combined use of narrative and numerical methodologies in foresight studies has been the subject of intense debate [5-25, 4].

The majority of foresight practitioners have used narrative approaches, because they consider the extrapolation from past and current data as insufficient to address future possibilities. Nevertheless, an increasing number of foresight practitioners argue that a combination of narrative and numerical methodologies are a promising but also challenging way to proceed $[5-6,8-9,15-18,23,26-29,30-31$, 106-110].

It is argued that more robust strategic tools emerge from the interaction between the narrative and numerical contributions [22, 32-34]. A combined narrative and numerical approach can strengthen strategy development [20]. The anticipation is that a Combined Simulation Approach (CSA) can be used to consider future options and risks by combining initiatives at the strategic, tactical, and operational levels. "CSA" is the researchers' formulation of an approach that has been discussed widely and combines two well-known 
methods: scenario analysis and computer simulation. This combination has been examined by the researchers in multiple settings [19, 35, 25, 106-110].

In this paper we will show how CSA proved to be useful for management in a Danish production company to examine different outsourcing/backsourcing strategies and their possible impact on the strategic, tactical, and operational levels. However, first we will clarify how we define narrative and numerical foresight methods. A methodology is numerical when it applies only statistical/mathematical tools and data $[36,12,10,9]$. It is narrative when it consists of stories written as words and/or visualized by drawings and words $[1,6,35,4$, 2]. CSA is characterized by the use of text, images, and numbers in a sequential and/or interactive manner. Finally, a participatory approach, regardless of whether narrative or numerical data is used, is one by which the outcome requires interactions between the foresight practitioners and relevant types of decision makers and stakeholders $[1,37]$. How participatory CSA was executed is explained later on in this paper.

The approach in this paper addresses complex, real-world problems. The modelling of this approach is iterative and can refer to the numerical modelling itself, but also to different sources of knowledge. In large organizations, specific knowledge issues are commonly distributed between several units. A context-oriented foresight approach necessarily involves many different knowledge sources in order to create a cohesive knowledge base. However, the participating members of the organization should not just be reduced to "information wells". A more beneficial approach that will motivate participants to think creatively and constructively is to provide an explicit contextual understanding of why and how their knowledge is important. This means that, throughout all of the different phases, the foresight process must remain transparent and contextualized [37-38, 1]. This also includes the validation [39-41] aspects of the modelling process, because the output from the different steps of the combined simulation approach is discussed on an ongoing basis with the stakeholders [38]. Before we describe how CSA was applied to a specific project, we will briefly introduce the two methods - narrative simulation and numerical simulation.

\section{Narrative simulation}

In this paper, scenarios are defined as different images of the future. Underestimating the importance of analysing future uncertainties can lead to policies and strategies that neither protect against possible threats, nor serve to take advantage of the opportunities connected to these uncertainties [21, 57-58]. Scenarios can help decision makers, planners and stakeholders gain an overview of and deeper insight into the possible outcomes of particular decisions. The special feature of scenario analysis is the long-term perspective on top of the combination of vision-making, storytelling and strategy formation [1]. Scenarios vary from brief statements to richly elaborated narratives, but are almost always based on the idea of a sequence of actions. To reach their target audience, narratives must be able to fascinate their stakeholders by containing points and events that clearly transcend the present state in a desirable direction. But they must also allow the stakeholders to identify with at least some of the actors or actions in them [1-2, 4, 59-61].

\section{Numerical simulation}

There are many different applications of numerical simulation, but the one used in this paper refers to the analysis of the consequences of a narrative scenario becoming a reality in the future [62]. A model is a representation of reality and not a complete replica of a real system [36, 62-63]. Simulation building should be strictly limited to inclusion of the relevant factors with respect to the needed results and evaluation [36, 64-67]. Numerical simulation consists of two aspects; the simulation tool, such as a simulation language, and the "modeler", who uses the simulation tool to build a model and analyse it. Computer simulation is needed to assist people in capturing the inbuilt dynamics of a feedback model, and in handling the complexity of a system, such as a large number of variables. It can also be used to reveal unexpected or unintended side effects that occur as a consequence of the deliberate actions. The program ProModel was used to create the numerical simulations. ProModel is a standard commercial off-the-shelf software program developed by the ProModel Corporation (www.ProModel.com). It is a discrete-event simulation technology that is used to plan, design and improve new or existing manufacturing, logistics and other operational systems (www.promodel.com). ProModel was considered easy to work with for both the designer and user as it has elements that the designer builds with using a minimum of programming and as the model can run with 
graphical representations and the output can also be shown in graphical representation which make it easy to communicate with the decision makers.

\section{The Combined Simulation Approach (CSA) - the model and discussion issues}

CSA's structure and processes are shown in figure 1.

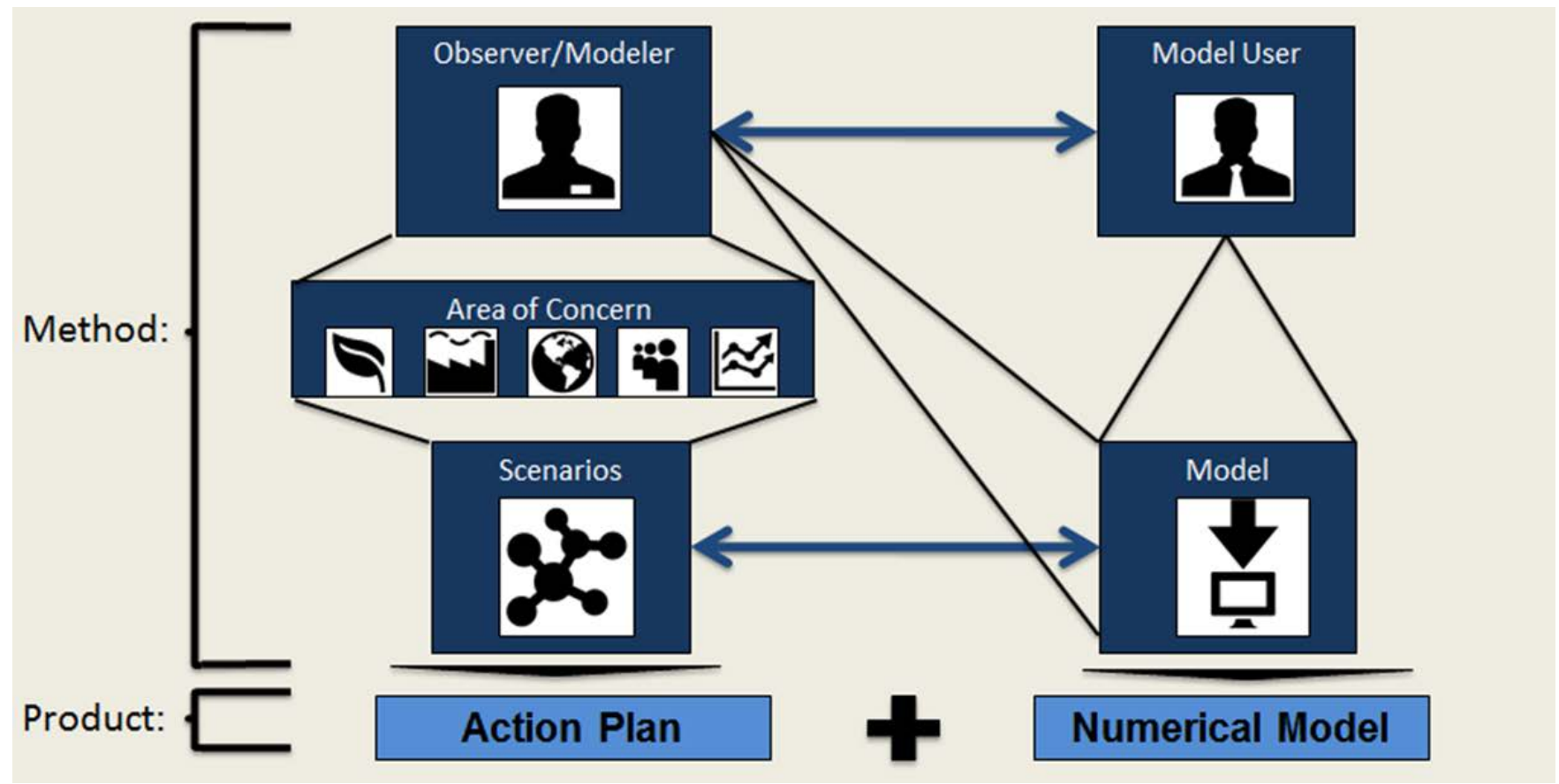

Figure 1: Combined Simulation Approach

Figure 1 shows the combination of narrative and numerical simulation and the elements involved in combining narrative and numerical simulation. It emphasizes the idea that the two methods should be used interactively, and that the stakeholders should be involved in the process through interaction with the observer/modeler or foresight practitioner. The CSA method is a collaborative approach that combines scenario building with computer simulation. This combination serves to enrich scenario creation. As can be seen in figure 1 above, the narrative component was in this case driven by the researchers/observer in cooperation with the stakeholders in order to find the area of concern and create relevant scenarios. The result from the narrative component of the CSA method was then used by the researcher/observer to build a numerical model in cooperation with the stakeholder/model user. This numerical model can be used by the stakeholder/model user to guide strategic decisions and also acts as a method to check the scenario assumptions and stimulate the generation of new ideas on how the scenarios could develop further. This is indicated by the arrow between the Scenarios and the Model in figure 1 that depicts continuous interaction between the two methods.

The CSA does not aim to model all aspects of reality, but to look at certain aspects of a system and then generate scenarios based on this area of concern. The narrative simulation can describe aspects that cannot be numerically simulated, and the numerical simulation can clarify the complexities and inconsistencies hidden in the narrative simulation. The combination and interaction of the two methods can enhance the clarification of both the narratives and the numerical models [19, 106-108].

Usually, the process will start with a scenario, and then proceed to translating this narrative into input and output variables usable in a computer model. This combined approach can also enhance creativity because 
the numerical model offers feedback for the narrative model, which can result in new and useful additions to the narratives. The improved narrative model can reciprocally impact the numerical model. In this way, an iterative process occurs between the two methods of simulation. This can illustrate how responsive an outcome is to changes in specific parameters and under certain conditions. The examination of the boundaries of the model can provide valuable insight into the resilience and usability of both models. This means that many different situations can be researched and adapted as things evolve. Making the models in visual form means that they can more easily be subjected to outside review. The model structure can also be re-used by either the model builder and/or the model user [19, 68]. This means that the stakeholders can follow the work on the scenarios and the computer simulations as they evolve over time and provide concrete feedback on them.

The main discussion issues in the literature regarding combining participatory narratives and numerical simulation methodologies in foresight studies can be summarized as:

- What are the relevant purposes of using combined participatory narratives and computer-based simulation [1, 2, 5, 32, 33, 19, 20, 69-71]?

- What are the possible strengths of such a combined approach [5, 1, 6-20, 22, 23, 25, 35, 72]?

- What are the possible risks or downsides of such a combined approach $[5,1,6-19,23,25,31,35$, 73-74]?

This paper will not discuss all possible purposes, but instead focus on CSA as a methodology to help decision makers and relevant stakeholders in a business context gain more systematic insight and the capabilities to consider both short and long-term issues, before they formulate a strategy and/or action plan for future activities. In addition, the paper will discuss the strengths and weaknesses of using mixed methods. In particular, the paper will reflect on the CSA approach as a means for increasing organizational insight into future issues, developing capacities to handle possible future events, and making decisions on the basis of combined simulations of possible paths that could be taken. However, the risk of there being inconsistency between the narratives and computer modelling, as well as the danger of missing connections between the simulation results and the contextual reality will also be discussed. In addition, the potential drawback of participatory biases in the development process of the narratives will be reflected on, as well as how this can be counteracted by involving stakeholders at different layers in the organization.

\section{The problem setting and scenario development in the company case study}

The following case study illustrates how CSA has been used to combine strategic, tactical and operational alternatives in a trans-national Danish company.

One of the company's vice presidents questioned whether lower costs were actually being achieved by outsourcing the company's production of tools and parts to Chinese suppliers. It was debated whether increasing automation was actually outperforming the lower salary levels in China, as these salaries had also started to increase. It was agreed that an examination of how the technological development might impact on the outsourcing/backsourcing strategies would be made. Throughout the process, the researchers attended the company several days a week and visited various departments to gather data and information relevant to the scenarios and the simulation, and to carry out interviews. Interviews were conducted with employees in the production department, the research and development department, the department for operations, and the financial department. These interviews with key actors were conducted to create possible pictures of the future. Data was collected to calculate the total cost of this strategy, and a numerical model was designed to make the simulation. The results were discussed with the key actors, and the narrative scenarios were further developed and refined. 
At the beginning, the Vice President of Component Manufacturing was the main stakeholder, and to start with, the researchers focused on this department in order to gather information about the Danish and the Chinese production as well as the outsourced functions. The researchers met with the Vice President of Component Manufacturing approximately two to four times during a month in order to discuss the findings and the development of the scenarios and simulation. The researchers also spoke with the other employees in the department in order to gather information about the department, and also specific data related to the production and outsourcing for the numerical simulation. After a period of two months, it was agreed that it was necessary for the researchers to gather information from other departments in the company. This was arranged so that the researchers spent approximately one month within the other departments listed above in order to verify and validate the data gathered at the production department and to gather additional information in relation to the outsourcing and production.

The original justification for offshoring/outsourcing in 2001 was based on the differences in salary levels for manual labor in Europe and Asia. However, the salary level in Asia had increased since 2001, and the company therefore considered whether they should move the factory to another country where the salary level would be lower. However, some departments did not think that this was viable in the long run and would have preferred the company to consider a more long-term, stable and competitive solution. Based on a reference scenario resembling the company's current situation, four new scenarios were developed. The development of the four scenarios took place through interaction with the managers. The four scenarios differing in the level of automation and the extent to which activities are in-house or outsourced - are shown below in figure 2 .

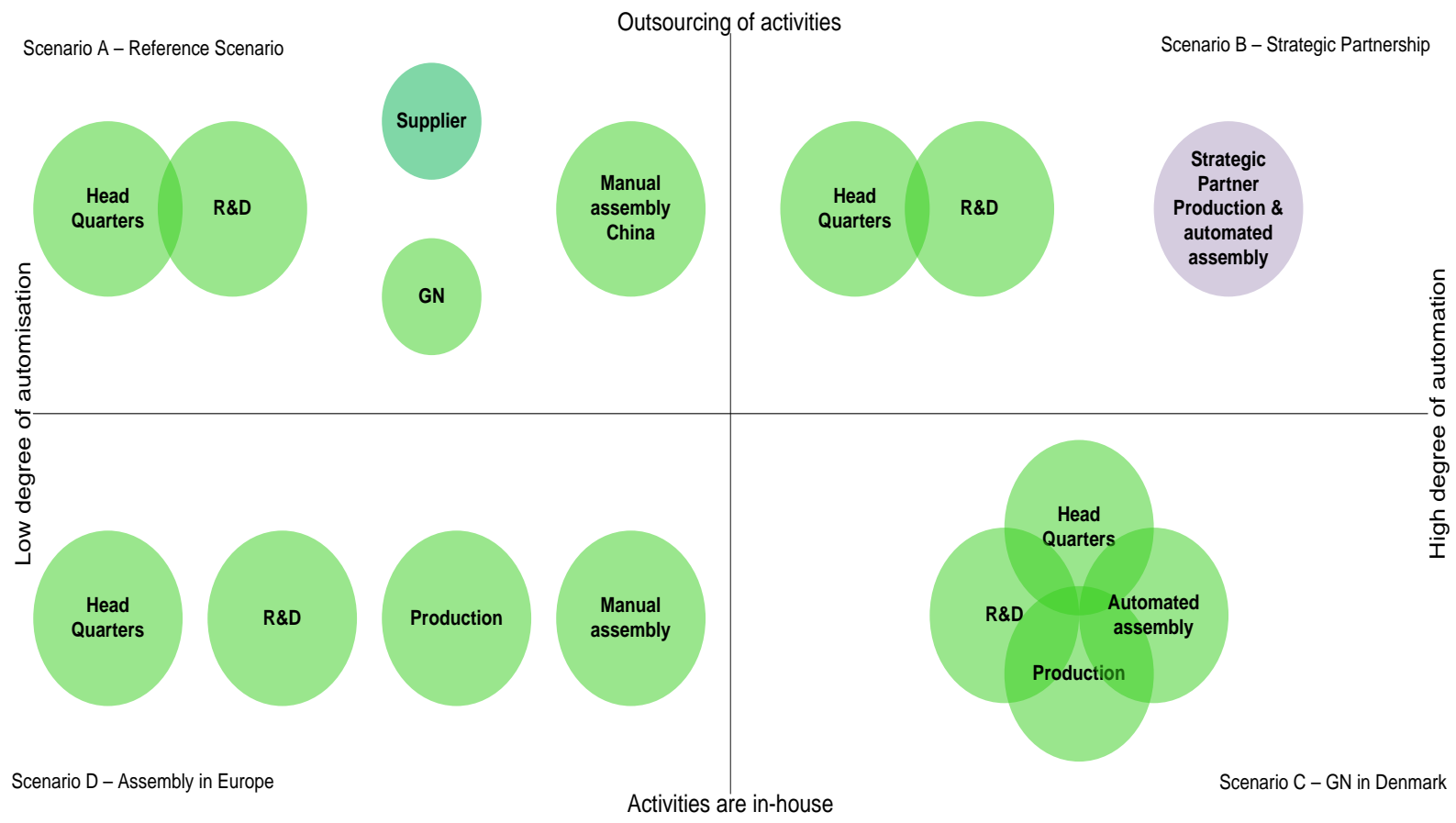

Figure 2: Four scenarios for outsourcing/backsourcing [68, 75]

Figure 2 shows the four scenarios and their different levels of automation and different degrees of outsourcing. In scenario A, the production of a product is divided between a supplier and the company. Assembly of the product occurs manually - as was the case at the time in the company. The scenario is constructed on the basis that the outsourcing strategy consistently focused on outsourcing a larger part of the production to suppliers in China. There are several uncertainty factors for scenario A, such as potential 
changes within the Chinese market and society, the risk of political disturbance, changes to the regional plan and increases in the salary level.

In scenario B, a strategic partnership with another company is formed. The strategic partner handles all production. The level of automation for product assembly is high in scenario B. The strategic partner has the competencies to carry out assembly using an automated process and at a competitive price. Most likely, the partner also has automated production of plastic parts and tools. This scenario was evaluated to take place further into the future as a fully automated assembly process was not considered realistic within the next 3-4 years. Even when the technology is mature, it is not a given that the company will invest in it because the business is characterized by small volumes, high complexity, small parts that have to be assembled precisely, and a relatively short product life cycle. This means that any return on the investment will be difficult to achieve. The scenario is nonetheless relevant as there is considerable potential in having an automated assembly process. Due to the fact that an automated assembly process is evaluated to be 7-10 years away, this scenario was not investigated further. It can, however, be particularly consequential, as an automated process could result in the salary level decreasing in relation to the total cost of a product, thereby making the location of the assembly process only of minor importance.

Scenario $\mathrm{C}$ also involves a high level of automation. The focus is on the company producing more internally. An automated assembly process means that assembly becomes more independent of salary level, which again means that the assembly can take place in Denmark. All activities in the company are gathered at one location, which can create synergies. The congregation of activities can result in reduced costs for location and property maintenance. The scenario will also result in a reduction of travel expenses for their own factory in China, such as in scenarios A and B. In addition, considerable resources are lost in day-to-day work due to travelling. All costs related to cooperation with suppliers will be eliminated, as well as the cost of communication. This scenario was not investigated further as it was considered that the technology would not mature enough in the near future to make it feasible.

Scenario D is characterized by a low degree of automation. The products are assembled manually in a factory located in an Eastern European country - such as the Czech Republic - but owned by the Danish company. The headquarters and research and development department are located in Copenhagen and the production site is in Denmark. The production site is expanded, and capacity is enhanced. The capacity at the tool shop at the headquarters can also be increased. All activities are in-house. The need for coordination and control of suppliers is eliminated, and employees can focus on their core tasks. Travel expenses are drastically reduced. Visits to the factory in Eastern Europe can be made in one day, in comparison to visits to the factory in China which typically take 5-7 days. This results in reduced travel and accommodation costs. Scenario D is highly realistic, but is not part of the company's current outsourcing strategy.

During the process of developing the four scenarios and through the cooperation with the Vice President, it became clear that the VP seriously questioned the current outsourcing strategy of the company. He requested the development of three sub-scenarios within scenario A in order to examine different possibilities.

\subsection{Scenario A}

The three sub-scenarios under scenario A differ from each other with regard to how much production is outsourced to third party suppliers:

- Scenario A1: The third party suppliers produce all plastic tools, all plastic parts and all hybrids.

- Scenario A2: The suppliers produce approximately 65\%, and the company produces the remaining $35 \%$.

- Scenario A3: The company produces 65\% plastic tools, plastic parts and all hybrids, and the Chinese third-party suppliers produce the remaining $35 \%$. The suppliers produce the most simple tools and parts. 
Through discussions with company management, it became evident that scenario A2 was interesting to pursue. Furthermore, the Vice President found it useful to identify the total costs related to the company's current outsourcing strategy for plastic tools in order to compare the current situation with new potential situations. In this scenario, the headquarters and the research and development department are located at the same address. Production is also located outside the major city as well as at a larger factory in China where the products are assembled. The company cooperates with two or three carefully selected Chinese suppliers and some suppliers from Northern Europe that specialize in making plastic tools. In relation to electronic components, the company cooperates with a large manufacturer in Thailand. The set up can be seen in the figure below.

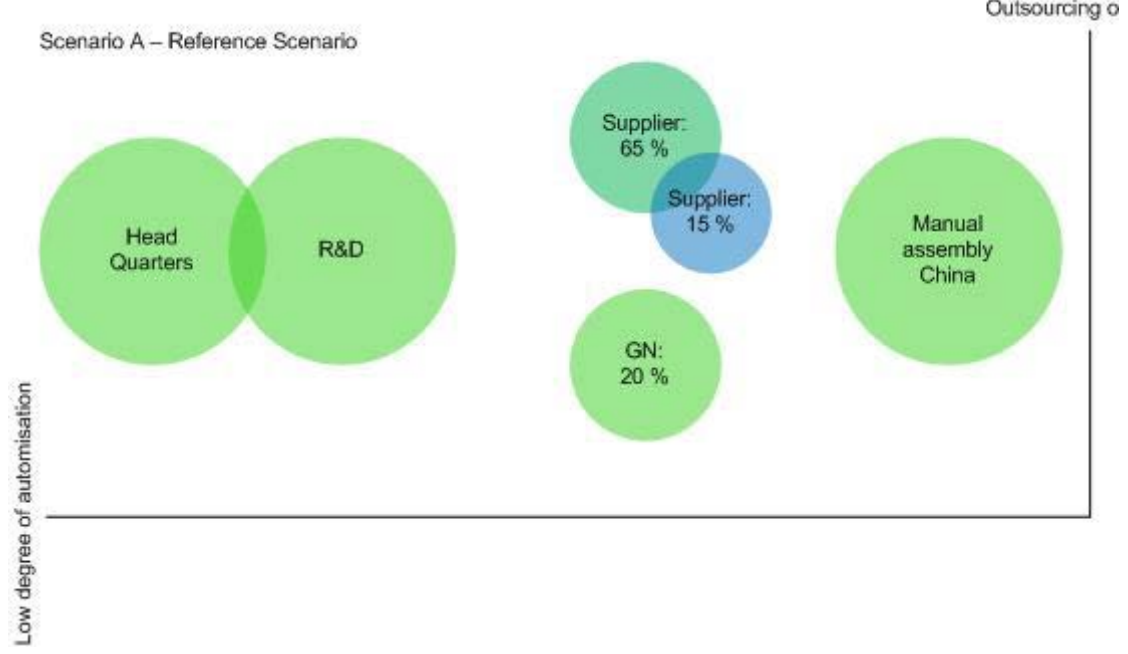

Figure 3: Scenario A2 [68, 75]

Scenario A2 poses a challenge in developing all of the necessary tools in time and at sufficient quality so that they can be used in the planned production of plastic parts. It is also a demanding task to get the production of plastic parts at the Chinese supplier to run in a timely manner. In reality, moving a tool from the company in Denmark to a supplier in China is a difficult task. The scenario was selected as a reference scenario because of its similarities to the current situation. Because of this, scenario A2 formed the basis of the first numerical simulation. The other scenarios can also be pursued and analysed in the same way that A2 will be in the following.

\subsection{The Numerical Simulation}

In order to question the current outsourcing strategy, it was necessary to identify the total costs. The impression that too many resources were being used to control and support the suppliers. This, in combination with the increasing prices in China, led to a questioning of the whole setup. There are different costs to consider when determining the total costs - such as indirect costs (that cannot be seen directly in the budgets) related to production. It could also be relevant to consider any hidden costs (such as $\mathrm{CO}_{2}$ emissions), but this falls outside the scope of this paper.

Some of the costs can be found in the budgets for the suppliers. Other costs, such as travel and accommodation for quality assurance visits to the suppliers, can also be found in the budgets, but they are not directly tied to the use of suppliers. The amount of time spent by consultants and employees at the suppliers' sites should also be calculated and added to the costs. The output of the model should therefore be the total costs in relation to producing a tool that can be approved and used in the plastic part production.

Based on several interviews, both at the production site as well as at company headquarters, a list of costs was developed together with management. This list was also inspired by information found in internal 
documents, strategies for the tools, and articles [69, 76]. It was important to discuss and formulate the list together with management to improve the different forms of simulation and make them more realistic. The list of different cost types is:

- Tool production

- Approval of tools

- Production of plastic parts

- Approval of plastic parts

- Repairs

- Materials

- Shipment

- Travel

- Investments in machines

- Maintenance of machines

- Qualification of suppliers (beginning)

- Qualification of suppliers and training (ongoing)

- Cooperation of improvement and innovation

- Adaptation of procedures

After the list had been made with management, it was also discussed and approved by several stakeholders. The list was used as a basis for specifying the input variables.

\subsection{Input variables}

The different input variables and the data related to those input variables will be described in the following. Because it was the indirect costs of outsourcing which were most interesting to examine, it was agreed that the cost of the suppliers would be used as an input variable. These costs could be seen directly in the budgets for the suppliers. They consist of costs for the number of tools the company had planned to produce in a given year, as well as the related costs per tool. The table below shows how many tools were planned for in a given year and the supplier responsible for each of these tools.

\begin{tabular}{|l|l|l|l|l|}
\hline & \multicolumn{4}{|l|}{ Expected division of tool production (number of tools) } \\
\hline Category & Tool shop & Scandinavian suppliers & $\begin{array}{l}\text { 1. Chinese } \\
\text { supplier }\end{array}$ & $\begin{array}{l}\text { 2. Chinese } \\
\text { supplier }\end{array}$ \\
\hline Plus 2 & 15 & - & - & - \\
\hline Plus 1 & - & 24 & 24 & - \\
\hline 0 & - & - & 25 & - \\
\hline Minus 1 & - & - & - & 19 \\
\hline Minus 2 & - & - & - & 15 \\
\hline
\end{tabular}

Table 1: Expected tools [68, 75]

The "category" refers to the level of complexity of the tool, where plus 2 is the most complicated tool. This particular tool is made by the tool shop in Denmark because, based on the company's experience, the suppliers were not able to produce this at the required quality level. The production prices for each tool can be seen in the table below. The price is related to the complexity of the tool and the supplier. The prices have been provided by the manager of the tool shop.

\begin{tabular}{|l|l|l|l|r|}
\hline & $\begin{array}{l}\text { Tool } \\
\text { shop }\end{array}$ & $\begin{array}{l}\text { Scandinavian } \\
\text { supplier }\end{array}$ & $\begin{array}{l}\text { 1. Chinese } \\
\text { supplier }\end{array}$ & $\begin{array}{l}\text { 2. Chinese } \\
\text { supplier }\end{array}$ \\
\hline Category & & 550,000 & & - \\
\hline Plus 2 & 414,000 & 350,000 & 138,000 & - \\
\hline Plus 1 & 272,000 & &
\end{tabular}




\begin{tabular}{|l|r|r|r|r|}
\hline 0 & 207,000 & - & 120,000 & - \\
\hline Minus 1 & 138,000 & - & 90,000 & 90,000 \\
\hline Minus 2 & 92,000 & - & 45,000 & 45,000 \\
\hline
\end{tabular}

Table 2: Tool prices in DKK $[68,75]$

Table 2 shows a more complete list of prices than is necessary to understand table 1 , but this is to illustrate that the tool shop in Denmark has the capacity to make all of the different categories of tools, only at a higher price for tools in category 0 , minus 1 , and minus 2 than the Chinese suppliers. These particular tools are comparatively less complicated and the Chinese suppliers can make them to the expected standard. The Chinese suppliers can also make tools in category Plus 2 and Plus 1, but they cannot deliver at the requisite quality level. The Scandinavian supplier can also make all tools, but they become too expensive in comparison with the Chinese suppliers for tools in category 0 , minus 1 , and minus 2 . The tool shop is actually cheaper than the Scandinavian supplier, but the company uses the Scandinavian supplier due to capacity limitations. In the numerical model, the prices of the tools were collected in one variable for each supplier.

To find the total costs, the indirect costs and the costs of resources must be added. Indirect costs were related to four different types of employees that travel to ensure the quality of the various tools. The four groups are:

1. Employees in R\&D who work with design of plastic parts and approval of the tools

2. Employees in Production who work with ramp-up and approval of the tools

3. Employees in Purchasing who select and cooperate with the suppliers

4. Employees in Purchasing in China who have the most contact with the Chinese suppliers

The costs include air travel, other transport, hotel and other living expenses such as food. The table below shows the costs of travel.

\begin{tabular}{|l|r|}
\hline \multicolumn{2}{|l|}{$\begin{array}{l}\text { Costs for Danish specialist per trip to a Chinese } \\
\text { supplier, in DKK }\end{array}$} \\
\hline Plane ticket - ordinary & 10,000 \\
\hline Accommodation & 5,000 \\
\hline Resources (40 hours at DKK 550) & 22,000 \\
\hline $\begin{array}{l}\text { Day's-notice plane ticket - immediate } \\
\text { problem }\end{array}$ \\
\hline
\end{tabular}

Table 3: Cost in DKK of travel to China $[68,75]$

Table 3 shows the costs for sending one specialist from Denmark to China to fix a specific problem (such as quality). Often such specialists are required to leave at short notice and therefore the plane ticket costs approximately DKK 10,000. Furthermore, there are the costs of staying in China for around one week of DKK 5,000. And the salary costs for the specialist approximate to one week's work at DKK 550 per hour. If there is an immediate problem and the specialist has to leave with only one day's warning, the plane ticket often escalates to a cost of DKK 25,000. These costs were entered into the numerical model based on the company's experience of how often these problems arose and then given a stochastic variation in the model.

These costs can also be seen in the numerical model:

- “I31 DK travel support 1st Chinese supplier" - for travels to the 1st Chinese supplier.

- " "I32 DK travel support 2nd Chinese supplier" - for travels to the 2nd Chinese supplier.

The names of these variables were also chosen by the researchers, and the "I" in front indicates that these were indirect costs. The resources used for project management were divided between the four types of 
employees listed above. The researchers worked together with the company's employees to make the specifications precise and detailed. A significant amount of time was used on coordination and communication in order to avoid misunderstandings between the company and the suppliers. The costs of the resources used to coordinate activities with the two Chinese suppliers are identified using the following two variables:

- "I21 1st Chinese supplier support” contains the costs related to the 1st Chinese supplier.

- "I22 Chinese supplier support" contains the costs related to the 2nd Chinese supplier.

The Chinese employees work together with the Chinese suppliers. They are all engineers. The costs of these employees are based on an estimate from Danish management. The variables represent salary costs and travel expenses for cooperating with the suppliers:

- "I11 support 1 Chinese supplier Engineer" - for the costs of working with 1st Chinese supplier.

- "I12 support 2 Chinese supplier Engineer" - for the costs of working with 2nd Chinese supplier.

The table below summarizes all the input variables described above.

\begin{tabular}{|c|}
\hline Input Variables \\
\hline $\begin{array}{ll}\text { - } & \text { B toolshop1 } \\
\text { - } & \text { B tool design supplier EU } \\
\text { - } & \text { B 1 Chinese supplier } \\
\text { - } & \text { B } 2 \text { Chinese supplier }\end{array}$ \\
\hline 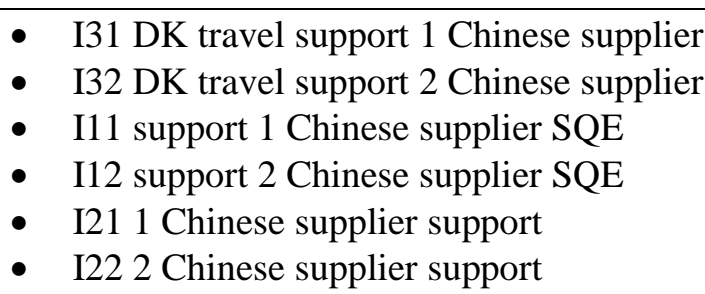 \\
\hline
\end{tabular}

Table 4: Input variables

The table shows the input variables that were developed for the model. These input variables are - as explained - found through data gathering and interviews with employees in the company to determine the outsourcing cost drivers. The names of the input variables reflect the names of the different suppliers and whether they represent known costs (B) or indirect costs (I).

\subsection{Output Variables}

The total cost of outsourcing was automatically calculated by the simulation as an output variable based on the known and indirect costs of outsourcing. It was especially interesting to focus on the total indirect costs of each supplier in order to compare the two suppliers in question. In the project, the difference will indicate whether there are extra costs for the company in using Chinese suppliers instead of Scandinavian suppliers.

\subsection{The Simulation Model}

With its roots in the initial idea to examine the total costs of outsourcing, and based on the above input and output variables, the numerical model was built. The model was constructed on the basis of how a tool is produced, meaning its path from beginning to end, and the costs involved in this process. For instance, a tool is first developed in Denmark by the tool shop and is then sent to China to be implemented in the overseas production. The Chinese site needs to learn about the new tool and how to use it, which in most cases can be complicated. Then the tool is integrated into production. This means that it is possible to follow the number 
of produced tools and in the same way track the different types of costs related to the production of each tool. Figure 4 shows how the model looks in the modelling program ProModel.

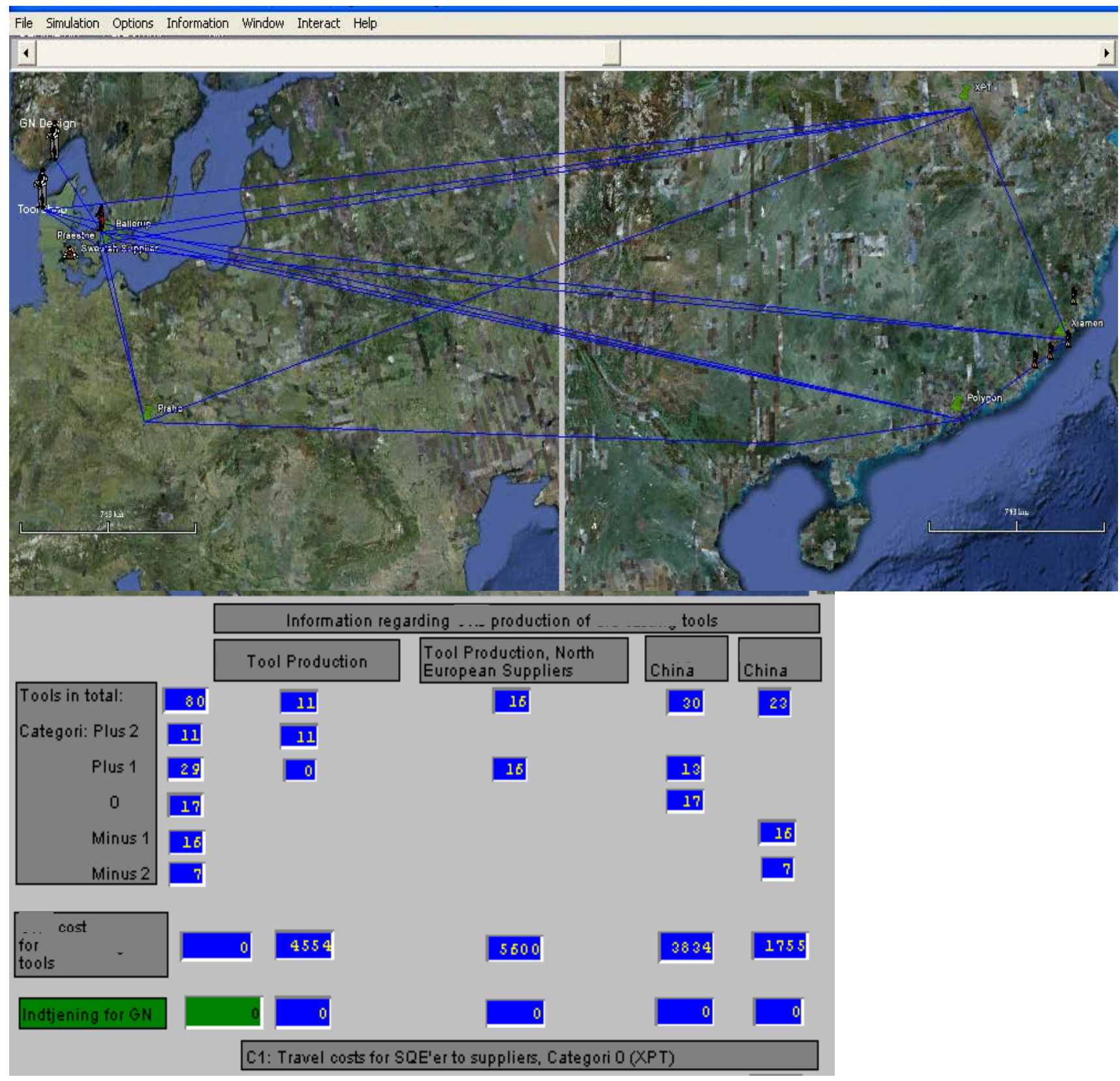

Figure 4: The simulation model [68, 75]

Figure 4 is a visual representation of the simulation model. The simulated time period is one year. During one year the company produces 122 tools. The model does not segment each year - rather, the tools are assumed to be produced concurrently throughout the year because the focal point for the company was to calculate the costs of producing the various tools during a year, rather than examining when the different tools were produced. However, the model can be constructed so that the different tools are produced at a given time.

The model is created in such a way that it is possible to track the number of tools made and the different types of costs relating to each tool. The total costs of producing the 122 tools can also be found. The 
numbers are shown as a function of time. The images at the top of the simulation show the Danish tool shop as well as the Chinese production site and the Chinese suppliers. The fields below the images show some of the numbers that are viewable throughout the simulation - such as the number of tools being made, the cost of the tools, travel costs, total costs, etc. This makes it possible to follow the model in real time. The development of costs over time can be seen in the next figure. Figure 5 shows the costs of having tools produced by the two Chinese suppliers. The direct costs involved in having the tools produced by Chinese supplier number 1 is shown by the green line and is by far the most expensive (company names have been removed for confidentiality reasons).

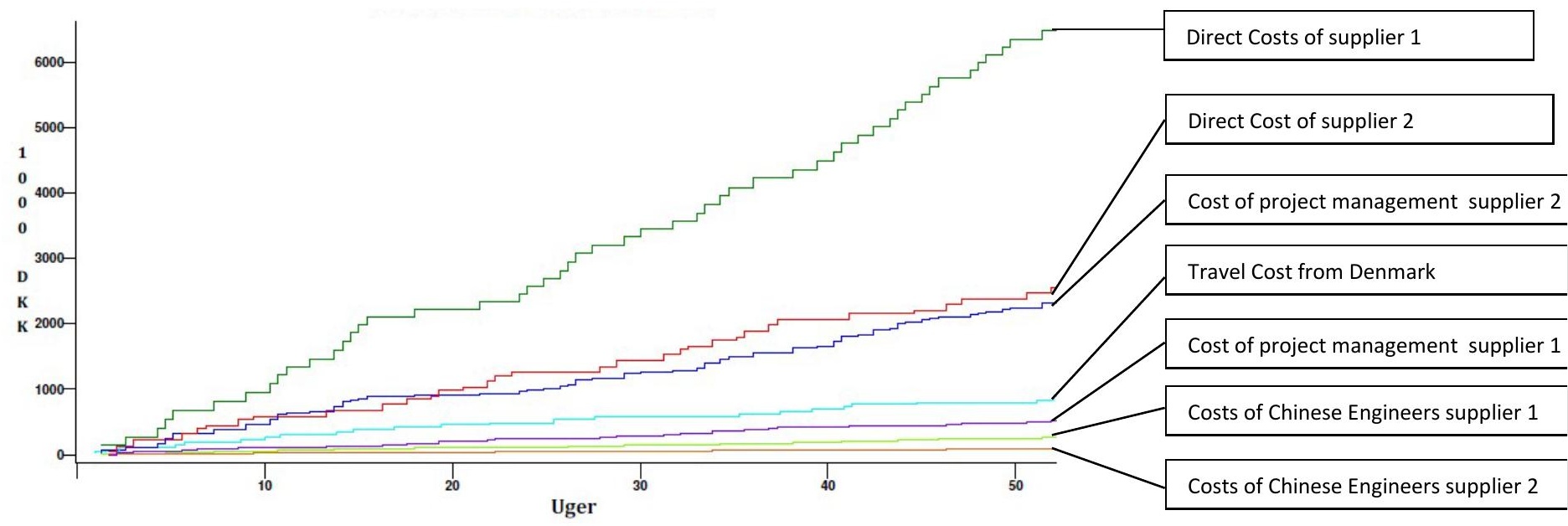

Figure 5: The output file seen graphically [68, 75]

The red line shows the costs involved in having Chinese supplier number 2 produce the tools. The other lines represent costs that form part of the total direct costs depicted by the green and red lines. For example, the cost of project management for the first Chinese supplier, shown by the blue line, are approximately $57 \%$ higher than the price on which the Purchasing Department would base their decision of which supplier to order the tools from. For the second Chinese supplier, which delivers less complex tools, the costs are 21\% higher. The simulation also shows the added costs in using the Chinese suppliers, which gives a true indication of the costs involved in using them, as compared to the prices on which the Purchasing Department will base their decision.

Applying the CSA process within the company culminated in different departments participating in development of and use of the scenarios and simulation models. Furthermore, opinions voiced by various persons across the different departments were noted and integrated into the scenarios. The visual part of the simulation and the fact that the numerical simulation was able to handle the complicatedness of many different data highlighted how the total costs involved in outsourcing were relevant to consider. The final report was sent to the company's top management and alerted them to the fact that there were costs involved in outsourcing and offshoring that had, so far, not been taken into consideration. The report was prioritized and management initiated an examination into the current outsourcing strategy. Furthermore, a crossfunctional team was established consisting of the Vice President of Component Manufacturing and key persons from Operations, Finance, and R\&D. The purpose of the team was to enhance knowledge sharing, communication, and cooperation between the different departments so that areas such as outsourcing costs could be handled and discussed.

The process described above involves both CSA facilitators and company personnel working in different areas and with different opinions. It can continue iteratively, thus proving that CSA can successfully be used to assist the strategy process. It is also possible that if CSA is applied to a broader user group within the company, and/or to external relations of the company, new ideas could emerge. In the cases where CSA has been applied, management found the results highly usable to quickly test the consequences of each scenario before decisions were made about future outsourcing/backsourcing activities. The visual modelling enhanced 
the creative interaction between company employees and the CSA facilitator. Moreover, the modelling was successfully used in several instances to translate tacit knowledge into explicit knowledge. This could be seen in examples where the production team in Denmark expressed (through the visual model) the total cost of suppliers for the supply chain team in Denmark, who received a visual representation. These positive results are also mentioned by Schirrmeister and Warnke [77]. Before the narrative and numerical models can be elaborated, the CSA facilitators have to collect knowledge from/of the company, the situation, the stakeholders and the mental models in order to determine and understand the needs and complexities. The interaction between the stakeholders and the CSA facilitators should take place concurrently in order for the stakeholders to gain ownership of the process and for the approach to be embedded within the company. Furthermore, this interaction is important because stakeholders increasingly become part of the development of companies and act more like co-developers. Figure 6 summarizes the iterative process of working with CSA.

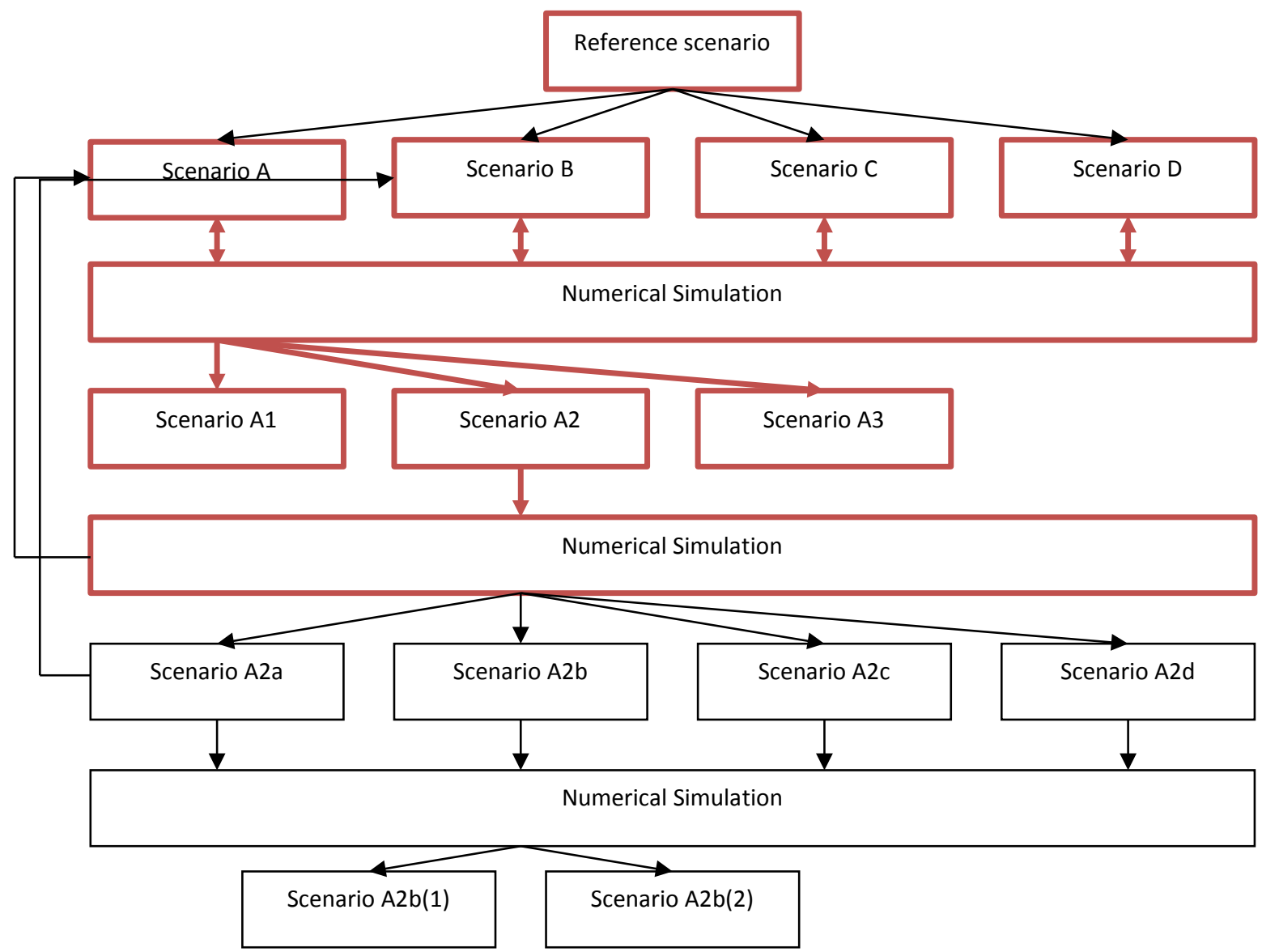

Figure 6: The interactive process of CSA

Figure 6 shows how the process started with a reference scenario, which in this process is defined as a scenario describing the company's current situation. This provided a good starting point because it also helped the CSA facilitators and the stakeholders clarify the kind of data needed for development of the numerical model. Based on the reference scenario and the interaction between CSA facilitators and stakeholders, the different scenarios (A, B, C, and D) were constructed. Interaction between the narrative and numerical simulation challenged some existing points of view as some of the scenarios that were anticipated to be most attractive for the company were found to be more expensive than expected when explored more thoroughly. During such a process it became apparent that certain knowledge was not shared or debated. Thus, CSA proved to be effective in drawing attention to complexities - such as the indirect aspects of total cost. The figure above shows that scenarios A, B, C, and D were simulated numerically and, based on the simulations, scenario A was chosen as the focus. This resulted in three further developments of scenario A - 
A1, A2, and A3. These three sub-scenarios were then simulated numerically and, based on these simulations, scenario A2 was further developed and so on. Figure 6 illustrates that the process is ongoing and iterative as it reflects the usual experience that new possibilities and obstacles continue to appear.

\section{Different Organisational Levels}

The process of working with CSA involves moving between the strategic, tactical and operational levels within the company. This was exemplified in this case where the first scenario and problem formulation occurred on a tactical level, based on the concerns expressed by the Vice President of Component Manufacturing regarding the actual costs of outsourcing. These concerns were then discussed, with the result that they were transformed into a reference scenario. To develop this scenario, the operational level was engaged through data collection and interviews with several employees in different departments to develop the different scenarios as precisely as possible, based on the information regarding production, outsourcing, and costs. Further, the actual values for the input parameters had to be found at the operational level, based on data for travel costs, production costs, supplier information, quality information etc. All of this information was checked at the tactical level with the Vice President of Component Manufacturing as well as other stakeholders. When the simulation had run and the results were produced, these were again checked at both the operational and tactical levels. The strategic level was involved at the end of the process when several scenarios and simulations had been made. This resulted in an awareness regarding the outsourcing costs, as well as an initiative at the tactical level where leaders from different departments were requested to meet on a more regular basis to discuss issues and potential development opportunities. It was found that CSA was an effective tool for strategy development, as it provided a structured approach to both inform and make strategic choices. Furthermore, CSA added a dynamic component to strategy development by facilitating several strategic conversations about a range of possible futures, challenging the participants in the process to look beyond the typical frameworks and change their mental models in relation to the company's outsourcing strategy. In addition to these conversations, CSA provided the opportunity to compare strategic options across multiple scenarios in relation to outsourcing. The CSA process moves between the different layers in the organization as illustrated below.

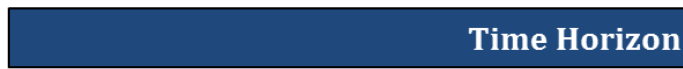

Horizon 1

Horizon 2

Horizon 3

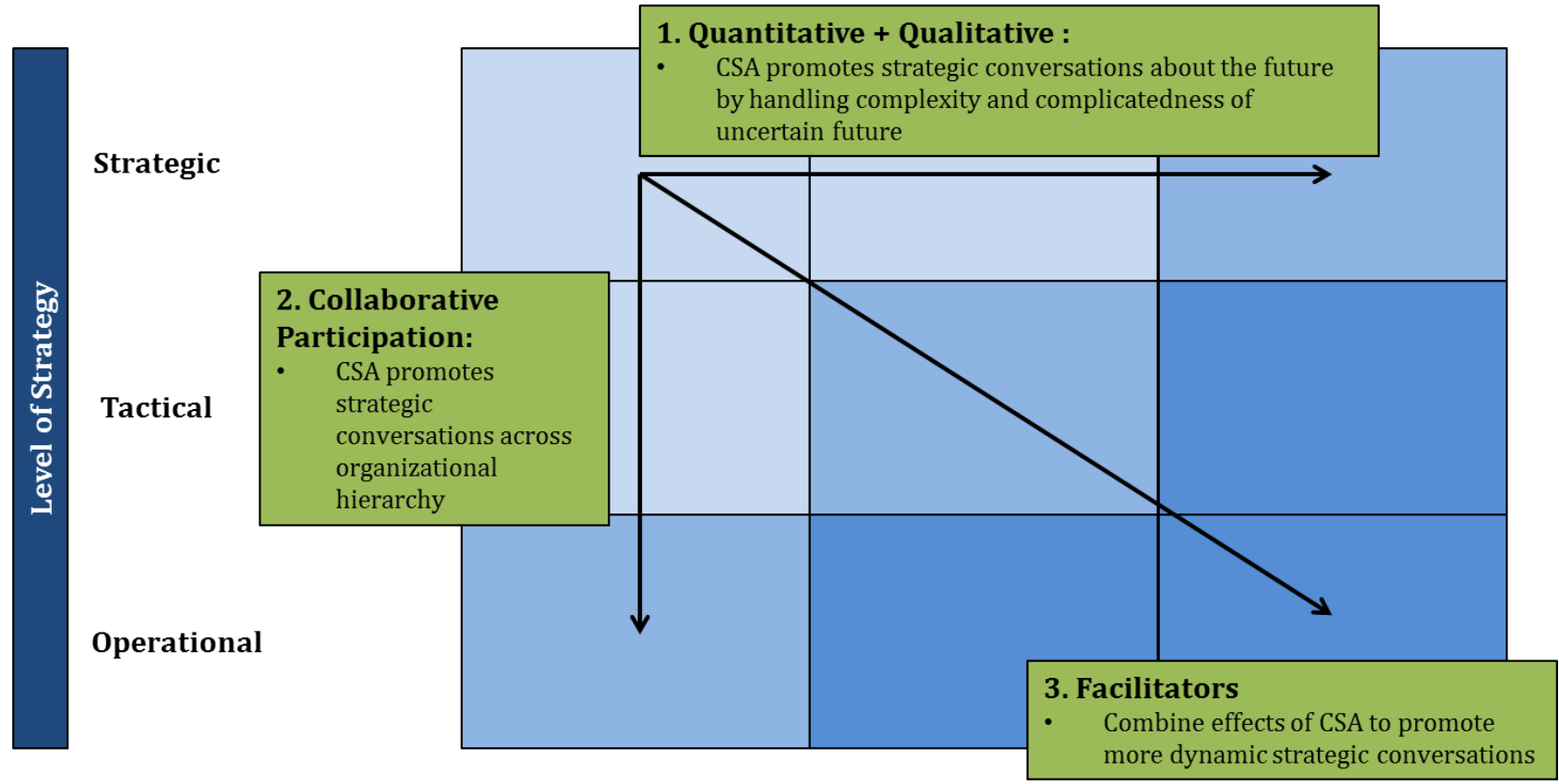

Figure 7: CSA as a tool for strategy development 
As the process is described in figure 6, it is argued that the combination of the qualitative scenarios and the quantitative computer simulation helps promote strategic conversations in the company - as was the example in this case where different scenarios regarding the outsourcing strategy were examined, both qualitatively and quantitatively. The conversations took place at different levels within the organization: the initial conversation started at the tactical level and then moved back and forth between the operational and tactical levels as the scenarios and simulations were elaborated on and validated, so that at the end of the process they could be discussed at the strategic level. Following this, the conversations were again brought to the tactical level with the cross-functional team that was established. To begin with, it was the facilitators/researchers that promoted the more dynamic strategic conversations through CSA, but as the process continued, the facilitators were needed less and less because the different stakeholders had been engaged and were able to manage the process themselves to a larger extent.

\section{Areas for using a combined simulation approach}

Within a company context, combined simulation approaches like CSA can be used to intensify the raising of awareness about possible challenges in the future ("awareness raising"), for capacity building of cooperation between decision makers, participatory stakeholders and facilitators of the process, as well as for policy building and decision making based on the simulations [1, 70-71]. These general purposes outlined in the literature will be reflected on in relation to the case study described above.

\subsection{Awareness raising}

The main objectives of awareness raising are the formulation and dissemination of socio-economic, environmental, infrastructural and/or technological trends that must be recognized and analysed before policy decisions are made [78-81]. Awareness raising by means of CSA includes the following types of activities:

- Trend-tracking, to detect weak and strong signals to gain insight into emergent drivers of change

- Risk analyses, to increase awareness of the potential risks attached to different routes

- $\quad$ Trust building, to agree on the needs, values, and benefits of using CSA for the target audiences

Awareness raising is a CSA activity that occurs before, during and after a specific CSA study is conducted. In practice, this was illustrated when one of the case company's vice presidents cast serious doubt on whether the company was actually achieving lower costs by outsourcing the production of tools and parts to Chinese suppliers. As explained, it was debated whether the increasing level of automation was in fact outperforming the lower salary levels in China because these salaries were also starting to increase. This debate led to trend-tracking to examine how the technological development could impact the outsourcing/backsourcing strategies. As the different departments did not agree on the outsourcing strategy, it was also necessary to carry out trust building in order to show all departments that there was a need to use CSA to examine the size of the indirect costs and whether another strategy could be more effective. This was carried out by making a reference scenario that resembled the company's current situation. This allowed the different statements to be tested before proceeding with CSA and the risk analyses of the four new scenarios that were developed. This allowed us to increase the awareness of the potential risks inherent in several different routes.

\subsection{Capacity building}

The main objectives of capacity building are to institutionalize interactions between CSA practitioners, stakeholders and policy makers. Here we draw a distinction between two institutional levels that are closely interrelated:

- Procedures, including structure, rules and methods of communication and decision making

- Roles, including the anticipations and interaction patterns between the institutionally related actors

Capacity building includes the following activities: 
- Skill development of the target audiences, increasing their abilities to participate in and apply the CSA studies. This also includes the development of concepts and practices for thinking about the future $-\mathrm{a}$ 'foresight culture' [82]

- Communication channels between CSA practitioners, stakeholders and policy makers

- Trans-disciplinary cooperation by the means of CSA workshops, enabling the stakeholders, policy makers and foresight practitioners to undertake more interactive roles and create new configurations of scenarios and road mapping

- Initiator skill development to use CSA to increase the number of new ideas and projects [83]

- Opponent skill development to use CSA to challenge the new ideas and assumptions [83]

Capacity building is closely related to awareness raising both in the sense of ensuring the effectiveness of the latter, and as a possible spin-off effect of awareness raising. The case company consisted of several departments with employees from all kinds of backgrounds, which emphasised the need for skill development and trans-disciplinary cooperation. This was done through a series of meetings, interviews, and workshops with the different departments in order to both understand them and to get them involved in the process. The active participation of the employees also meant that the communication channels were open as there was direct contact between all the departments. The general scenarios were continuously refined to more specific scenarios through interaction with the Vice President and other stakeholders in the company, indicating that both initiator and opponent skills were developed through the use of CSA.

\subsection{Policy building}

Policy building includes creating the process, facilitation of the process and the consequent output of the process - whether these are policy statements, laws, standards, strategies, research priorities and/or practices based on the resulting policies in question. In general, policy building in this sense can help policy makers to make short-term decisions framed by a long-term perspective. It provides them with methods to think more interactively and systematically, as compared to the often fragmented ways of making day-to-day policies [84-85].

Policy-building activities include the sub-types listed below:

- Reformulation of current issues, CSA facilitation may help participants to draw attention to new aspects of current issues, as longer term perspectives become clearer. Such a reformulation can "open the window" for new political trade-offs and/or innovative systems.

- Putting new issues on the current agenda, CSA can draw attention to new issues that are not yet on the political agenda. Due to the combined long- and short-term orientation of foresight studies, political issues that are not yet visible or recognized on the current agenda can be identified and included in a policy-making process. In a corporate context this means that new business fields are explored.

- Pointing at emergent issues/risks, The combination of long-term and short-term approaches in CSA can provide information about the cumulative comprehensive effects of current 'harmless' effects of a certain political decision [86].

- Identification of future technologies, CSA studies can identify emerging technologies that may solve current problems within the framework of the present policy decision or by developing a new political strategy.

The interactive process of CSA (figure 6) is an example of this, as the process describes the intention to use CSA to link the long-term perspective with the short-term perspective. Starting from a reference scenario resembling the current strategy, it is possible to reformulate the current issues by moving in depth through multiple scenarios that become increasingly detailed and short-term through the interaction. This can also reveal new possible obstacles and put new issues on the current agenda. This was seen in our case because the Vice President found it interesting to identify the total costs for the company's current outsourcing strategy for plastic tools in order to compare the current situation with new possible situations. This had not been considered before, because the company had focused on reducing the actual salary level by outsourcing production. It was therefore interesting to examine different variations of scenario A2 in order to point at 
emergent issues/risks for each possible scenario. Some scenarios also pointed to future technologies - as a fully automated assembly process was not considered to be realistic within the next 3-4 years.

\section{Strengths and pitfalls}

Foresight studies have observed several advantages of combining narrative and numerical simulation. Based on our experience from different sectors (such as healthcare, production and the maritime industry), interactive and participatory CSA makes it possible to incorporate a range of different values, interests and experiences from heterogeneous stakeholders and experts in the field [87].

It thereby becomes possible to maintain complexity without losing an overview of the impacts that key drivers have on the issues simulated in the models. In sum, the combined simulation approach increases the level of confidence that the decision makers and stakeholders can have in the models, and motivates them to reflect on and use the outputs. However, there are also several pitfalls in the use of this combined approach [22, 88-91].

\subsection{Pitfall: Participatory biases}

One of the strengths of the method is that both the scenarios and the numerical simulations are developed through close interaction with stakeholders. But such close cooperation can also be a problem if the CSA practitioners become biased. This means that they must remain aware of the risk of being too heavily influenced by some of the stakeholders and their opinions. It also implies that it is a time-consuming process, meaning that the stakeholders have to agree that they are willing and able to put in the time necessary to ensure a successful CSA output [87, 92-94]. In our project, it was solved by involving many different departments in the process, and making sure that multiple different stakeholders participated and contributed to the narrative and numerical simulation.

\subsection{Pitfall: Reproduction}

Using CSA can also run the risk of simply reproducing existing assumptions [1, 52-53] - particularly when scenario development only follows mainstream thinking. To prevent such a useless approach, several authors argue for a stronger emphasis on ultra-creative scenarios and an effective interaction with numerical simulation [5, 19, 57, 73]. In order to reduce the likelihood of experiencing this downside for our project, in the second part of the analysis, we elected to pursue a scenario that was dismissed by the company in the first part of the case.

\subsection{Pitfall: Number fascination}

Peter Drucker's mantra, “if you can’t measure it, you can’t manage it” still has momentum among decisionmakers in private and public organizations. In CSA studies, numbers may look more certain than they really are [95-96]. Therefore, it is important that numbers require us to be more specific and precise in the description of the input and output variables of the models. This provides a beneficial base for continuous discussion and dialogue. The benefits of using quantitative models in foresight studies seem to lie more in their facilitation of a comparison between decision alternatives relating to specific scenarios than in their absolute values [97]. In order to counteract the pitfall of "number-fascination”, CSA practitioners must explicitly state the different types of ignorance (known unknowns, unknown knowns and unknown unknowns) [98]. It is essential that the CSA practitioners clearly explain the purposes of using numbers. Furthermore, CSA's focus is to develop the narrative and the numerical simulations in parallel in order to avoid fixation on one approach.

\subsection{Pitfall: Creating hyperopia}

Foresight practitioners in general recognize the normative view that foresight studies contribute to the resilience of strategic planning. However, little research exists to explain when contextual conditions make its application inappropriate - for instance, when strong emphasis on foresight results in hyperopia in which the long-term perspective is favoured to the extent that short-term considerations are marginalized [74]. In this project, hyperopia was avoided because the company took a rather short-term perspective. 


\subsection{Pitfall: Missing the connection between the narrative and numerical approach}

The process for creating the narrative simulations must be transparent and explicitly described. But there is still a chance that a number of inconsistencies between the narrative and numerical simulation models will occur. Some authors believe that achieving consistency between the narrative and numerical outputs is “...one of the weakest links" [99]. Along similar lines, Kosow has pointed out that,

“....Overall, transformation rarely allows a perfect fit between the driving forces described by the storylines and those needed as input parameters by the models" [35].

The question is, what does "a perfect fit" mean? As already pointed out, a full translation of narratives into numbers is perhaps unrealistic, but less can also be useful. Our point is that an important task is carried out when a foresight approach like CSA creates a continuous interaction between decision makers, stakeholders and foresight practitioners with the common purpose of developing and discussing possible strategies for the future. An "imperfect fit" may also initiate fruitful conversations $[3,100]$ and help decision makers to achieve a deeper and more systemic way of thinking before they make their decisions.

\section{Conclusions}

Narrative simulation makes it possible to explore paradoxes and opposing interests through alternative imaginations of future situations [101-104]. Numerical modelling of selected parts of the scenarios can supplement the narrative analysis via a sensitivity analysis that examines the reaction of certain output variables to a certain change of input values [25, 72]. Since narrative simulation has an important function with regard to involving stakeholders in the strategic and implementing activities, it can address many strategic issues within companies. These include corporate social strategies, product development, market development, environmental strategies, optimization strategies, cost-reduction strategies and so on. Narrative simulation facilitates an exploration of possible functional linkages, and numerical simulation can add further knowledge about the extent to which these relationships influence each other.

The process model described above shows that it is possible to work with both the breadth and the depth of developing strategies. It is possible to develop many conceivable futures and investigate their potential because the number of scenarios developed is determined by the stakeholders and CSA facilitators. But it is also possible to drill down to a very detailed level and examine each scenario in depth in relation to several parameters, according to, for example, technology management foresight. This is also the new part of the method, as it is possible to reach a very specific level through the disciplinary approach. This also emphasizes that if a strategy is to encompass and shed light on the various complexities in such a process, it should be developed across the different layers of the organization [61, 103].

CSA can be used to enhance awareness raising, capability building, and policy building as it can be used for practical present-day decision-making - while at the same time it improves the decision-makers' capacities to view those decisions in relation to possible long-term impacts. However, it is also important to mention that there are a number of pitfalls - some of them briefly outlined in this paper. Though we regard CSA as a major step in further anchoring foresight in decision making, there are still a number of dilemmas to consider.

\section{Implications for further research}

Our dilemma can be stated as: How can CSA be sufficiently contextualized and tailored so that it motivates decision makers to use it and, at the same time, avoids the "puppet" role that legitimizes already anchored expectations and chosen paths of development?

As pointed out by van Lente, “... Statements about the future are not innocent descriptions but are performative...Once they are voiced and circulated, they will legitimize, steer and coordinate efforts also for unintended purposes. They may be used, for instance, to strengthen the legitimacy of selected priorities”. [105] 
These dilemmas are relevant not only to the use of CSA, but to foresight approaches in general. However, because CSA is intended to be carried out through the continuous interaction between decision makers and other stakeholders - rather than conducted in an "isolated ivory tower" - the risk of being forced into a "puppet" role is more serious than in more traditional academic foresight studies. More research on and clarification of how foresight practitioners can cooperate interactively with stakeholders while retaining sufficient distance to still be able to claim the principle of "arms-length" is needed.

Another dilemma is that ever-increasing computer power may have broad and challenging implications for the dynamic balance between narrative and numerical simulation. The emerging functions of computation will become accentuated [73]. It is not necessarily a negative tendency, but it can weaken the CSA principle of allowing the narratives to guide the creation of input and output variables for the numerical model, as suggested in this paper. A new social role for computation may include the emergence of steering systems which can develop the narratives in direct interaction with stakeholders. The foresight practitioner's role may then be reduced to influencing the steering systems before the interaction takes place and assessing the output when the interaction process has been conducted. This is not necessarily what will happen, but it might be one of several possible future outcomes. Therefore, foresight practitioners should consider how their future roles might change and what skills they might need to develop in response.

\section{Acknowledgements}

The methods are currently being further developed in a project funded by The Danish Maritime Fund.

\section{References}

[1] L.B. Rasmussen. “Interactive Scenario Analysis”, In Facilitating Change - Using interactive methods in organisations, communities and networks LB Rasmussen (ed), pp. 140. Denmark, Polyteknisk Forlag (2011). [2] K. Van Der Heijden. "Scenarios - The Art of Strategic Conversation”, West Sussex, John Wiley \& Sons, Ltd (2005).

[3] K. van der Heijden, R.Bradfield, G.Burt, G.Caims, G.Wright. "The sixth Sense: Accelerating Organisational learning with Scenarios”, John Wiley and Sons, LTD, US (2002)

[4] M. Lindgren and H. Bandhold. "Scenario Planning. The link between future and strategy" UK, Palgrave Macmillan (2009).

[5] K. Haegeman, E. Marinelli, F. Scapolo, A. Ricci, A. Sokolov. "Quantitative and qualitative approaches in Future-oriented Technology Analysis (FTA) - From combination to integration”, Technol. Forecast. Soc. Chang 80 (2013) 386-397

[6] E. Kemp-Benedict. "Converting qualitative assessments to quantitative assumptions: Bayes' rule and the pundits wager”, Technol. Forecast. Soc. Chang 77 (2010) 167-171

[7] M. Wood, C.Welch. "Are qualitative and quantitative useful terms for describing research?”, Methodol Innov. Online 5(1) (2010), 56-71

[8] C. Teddlie and A. Tashakkori. "Foundations of mixed method research: Integrating Quantitative and Qualitative Approaches in the Social and Behavioral Sciences”, Sage Publications (2009)

[9] R.B Johnson and A.J. Onwuegbuzie. "Mixed Methods Research, A Research Paradigm Whose Time Has Come”, Educational Researcher, 33(7) (2004) 14-26.

[10] W.K. Olsen. "Triangulation in social research: qualitative and quantitative methods can really be mixed”, in: M. Holborn, Haralambos (Eds.), Developments in Sociology, Causeway press, 2004

[11] H. White. "Combining quantitative and qualitative approaches in poverty analysis”, World Dev. 30(3) (2002) 511-522

[12] K.R. Howe. “Getting over the quantitative-qualitative debate”, Am. J. Educ. 100 (1992) 236-256

[13] S. Mathison. “Why triangulate?”, Educ. Res. 17(2) (1988), 13-17

[14] T.D. Jick. "Mixing qualitative and quantitative methods: triangulation in action”, Adm. Sci. Q. 24(4)

(1979) 602-611

[15] M.Y. Feilzer. "Doing Mixed Methods Research Pragmatically, Implications for the Rediscovery of

Pragmatism as a Research Paradigm”, Journal of Mixed Methods Research, 4(1) (2010) 6-16.

[16] J.H. Kwakkel and E. Pruy. "Exploraty Modeling and Analysis, an approach for model-based foresight under deep uncertainty”, Technol. Forecast. Soc. Chang 80 (2013) 419-431 
[17] F. Scapolo and E. Cahill. "New horizons and challenges for future-oriented technology analysis: proceedings of the EU-US scientific seminar: new technology foresight, forecasting and assessment methods”, in: JRC Technical Report, EUR 21473 EN European Commission (2004)

[18] J. Brannen. "Mixed methods research: a discussion paper”, NCRM Methods Review Papers, NCRM/005 Unpublished (2005) Available at: http://eprints.ncrm.ac.uk/89/1/MethodsReviewPaperNCRM005.pdf.

[19] E. Kemp-Benedict. "From Narrative to Number, A Role for Quantitative Models in Scenario Analysis", citeseerx. ist. psu. edu [last accessed 14 January 2013].

[20] J.K. Hazy, W.P. Millhiser and D. Solow. "Mathematical and Computational Models of Leadership, Past and Future", In Complex Systems Leadership Theory, New Perspectives from Complexity Science on Social and Organisational Effectiveness, JK Hazy, JA Goldstein and BB Lichtenstein (ed), pp. 163-193. Mansfield, US, ISCE Publishing. (2007).

[21] M.K.Peter and D.G.Jarratt. “The practice of foresight in long-term planning”, Technol. Forecast. Soc. Chang 80 (2013)

[22] A. Bryman. “Barriers to integrating quantitative and qualitative research”, J. Mixed Methods Res.1(1): 8-22 (2007)

[23] F.G. Castro, J.G. Kellison, S.J. Boyd, A. Kopak. "A methodology for conducting integrative mixed methods research and data analyses”, J. Mixed Methods Res. 4(4): 342-360 (2010)

[24] S. Hirch, P. Burgraf and C. Daheim. "Scenario planning with integrated quantification -managing uncertainty in corporate strategy building”, Foresight 15(5): 363-374 (2013)

[25] P. Loucopoulos: "Evaluating Scenarios by Simulation", In Scenarios, Stories, Use Cases - Through the Systems Development Life-Cycle, IF Alexander and N Maiden (ed), pp. 411-428. West Sussex, England, John Wiley \& Sons, Ltd (2004).

[26] B.P. Bryant , R.J. Lempert. "Thinking inside the box, A participatory, computer-assisted approach to scenario discovery”, Technol.Forecast.Soc.Chang 77: 34-49 (2010)

[27] A. Bãban. "Reconceptualisation of the devision between quantitative and qualitative research methods, cognition, brain, behaviour”, Interdiscip. J. XII (4): 337-343 (2008)

[28] P. Bazeley. "Issues in mixing qualitative and quantitative approaches to research", in, R. Ruber, J.

Gadner (Eds.), Applying Qualitative methods to marketing Management research, Palgrave Macmillan, Hampshire, United Kingdom, (2004)

[29] R. Cameron. “Mixed methods research: the five p’s framework”, Electron. J. Bus. Res. Methods 9(2): 96-108 (2011)

[30] K.R. Howe. “Against the qualitative-quantitative incomtability or, Dogmas die hard”, Educ. Res. 17: 10-16 (1988)

[31] J.E.M. Sale, L.H. Lohfeld and K. Brazil. "Revisiting the qualitative-quantitative debate: Implications for mixed-methods research”, Qual. Quant. 36(1): 43-53 (2002)

[32] M. Kljajic, I. Bernik and A. Skraba. "Simulation Approach to Decision Management”, Simulation, 75(4): 199-210 (2000).

[33] R. Phaal, C. Farrukh and D. Probert. "Roadmapping for strategy innovation - Aligning technology and markets in a dynamic world”, Cambridge, UK, University of Cambridge, Centre for Technology

Management (2010).

[34] M. Baramichai, E.W. Jr. Zimmers and C.A. Marangos. "Agile supply chain transformation matrix, an integrated tool for creating an agile enterprise”, Supply Chain Management - an International Journal, 12(5): 334-348 (2007).

[35] H. Kosow. "Consistent context scenarios: a new approach to story and simulation”, Fourth

International Sevilla Conference on Future-Oriented Technology Analysis (FTA) Seville , 12-13 May, 1-14 (2011)

[36] M. Pidd. “Computer Simulation in Management Science”,West Sussex, England, John Wiley \& Sons, Ltd (2004).

[37] B. Rasmussen, P.D. Andersen and K. Borch. "Managing Transdisciplinarity in Strategic Foresight”, Creativity and Innovation Management, 19(1): 37-46 (2010). 
[38] U. Gallati and U. Wiesmann. "System Dynamics in Transdisciplinary Research for Sustainable Development”, In Research for Sustainable Development, Foundations, Experiences, and Perspectives, U Wiemann and H Hurni (ed), pp. 345-360. Bern, Switzerland, Geographica Bernensia. (2011). [39] J.D. Illgen. "Simulation Validation and Management”, Proc.SPIE2495, Distributed Interactive Simulation Systems Application, 104 (1995).

[40] R.G, Sargent. "Verification and validation of simulation models", Proceedings of the 2005 Winter Simulation Conference (2005).

[41] L.E. Champagne \& R.R. Hill. "Simulation validation with historic outcomes", Proceedings of the 2005 Winter Simulation Conference (2005)

[49] C.M. Macal and M.J. North. "Introductory Tutorial: Agent-Based Modeling and Simulation”, Proceedings of the 2011 Winter Simulation Conference (2011)

[50] S.F. Railsback and V. Grimm. "Agent-based and Individual-based Modeling: A Practical Introduction”, Princeton University Press (2012)

[51] W. Rand and R.T Rust. "Agent-Based Modeling in Marketing: Guidelines for Rigor”, International Journal of Research in Marketing 28(3): 181-193 (2011)

[52] B.L Heath, R.R. Hill and F. Ciarallo. "A Survey of Agent-Based Modeling Practices (January 1998 to July 2008)", Journal of Artificial Societies and Social Simulation 12(4), Article 9 (2009)

[53] M.L. Zellner. "Embracing Complexity and Uncertainty: The Potential of Agent-Based Modeling for Environmental Planning and Policy”, Planning Theory \& Practice 9(4): 437-457 (2008)

[57] I. Tuomi. “Foresight in an unpredictable world”, Tech.anal., stra. Manage. 24(8): 735-751 (2012)

[58] I. Miles. "The development of technology foresight: A review”, Tech. Forecast Soc. Change 77: 1448$1456(2010)$

[59] L.D. Brabandere, A. Ivy. "Scenarios and creativity Thinking in new boxes", Technol. Forecast Soc. Chang 77: 1506-1512 (2010)

[60] C. Bezold. "Lessons from using scenarios for strategic foresight”, Technol. Forecast. Soc. Chang 77: 1513-1518 (2010)

[61] R. Vecchiato and C. Roveda. "Foresight in corporate organisations", Technology Analysis \& Strategic Management, 22(1): 99 (2010).

[62] P. Jacobsen. "Simulation”, Unpublished compendium notes used in the course 'Simulation in Production and Services', Technical University of Denmark, Department of Management Engineering (2005).

[63] J. A. Sokolowski and C. M. Banks. "Principles of Modeling and Simulation - A Multidisciplinary Approach”, New Jersey, John Wiley \& Sons (2009)

[64] P. Jacobsen. "Production of Modularised Product Systems", In IFAC-MIM Conference on

Manufacturing, Modelling, Management and Control (2004).

[65] S.M. Ross. “Simulation”, US, Elsevier Academic Press (2006).

[66] C. Harrell and K. Tumay. "Simulation Made Easy - A Manager's Guide”, Georgia, US, Engineering \& Management Press (1995).

[67] K. Chaharbaghi. "DSSL II, A Powerful Tool for Modelling and Analysing Complex Systems”, International Journal of Operations and Production Management, 11(4): 44-88 (1991).

[68] M.S. Hansen. "Strategic Simulation - Support of Innovation and Operation in Distribution and Production Networks”, Doctoral dissertation, Technical University of Denmark, Department of Management Engineering (2012).

[69] P.A.v.d.Duin and E.d.Hartigh. "Keeping the balance: exploring the link of futures research with innovation and strategy processes”, Technol. Anal. Strateg. Manage. 21(3): 333-351 (2009).

[70] R. Johnston. "Developing the capacity to assess the impact of foresight”, Foresight 14 (1): 56-68 (2012). [71] M. Rader and A.L. Porter. "Fitting future-oriented technology analysis methods to study types”, in: C. Cagnin, M. Keenan, R. Johnson, F. Scapolo, R. Barre (EDS.), Future-oriented technology Analysis: Strategic Intelligence for an Innovative Economy Springer Verlag, Berlin and Heidelberg, (2008).

[72] J.S. Baldwin, P.M. Allen and K. Ridgway. "An evolutionary complex systems decision-support tool for the management of operations”, International Journal of Operations \& Production Management, 30(7): 700720 (2010). 
[73] D. Loveridge, O. Sarita. "Ignorance and uncertainty: influences on future-oriented technology analysis”, Technol. Anal. Strateg. Manage. 24(8): 753-767 (2012).

[74] G. Burt, D.J. Mackay and A. Perchard. "Managerial hyperopia. A potential unintended consequence of foresight in a top management team?”, Technol. Forecast. Soc. Chang 80m (2013).

[75] S. Arnklit. “Outsourcing scenarier I Kina - Belyst ved strategisk simulering”. Unpublished master thesis, Technical University of Denmark, Department of Management Engineering (2011).

[76] A.K. Bharti, S.K. Dwivedi. "Design of an Analytical and Foresight based Strategic Model for eGovernance in Public Transportation”, Computational Intelligence and Information Technology 250 (2011), 615-620

[77] E. Schirrmeister, P. Warnke. "Envisioning structural transformation - lessons from a foresight project on the future of innovation”, Technol.Forecast.Soc.Chang 80: 453-466 (2013).

[78] C. Battistella. "The organisation of Corporate Foresight: A multiple case study in the telecommunication industry”, Technol.Forecast.Soc.Chang 80 (2013).

[79] P.D. Smedt, K.Borch, T.Fuller. "Future scenarios to inspire innovation”, Technol.Forecast.Soc.Chang 80: 432-443 (2013).

[80] J. Schippl, T. Fleischer. "A problem-oriented categorization of FTA-methods for transport planning, Foresight”, 14 (4): 282-293 (2012).

[81] L. Georghiou, J.C.Harper. "Rising to the challenges- Reflections on Future-oriented Technology Analysis", Technol.Forecast.Soc.Chang 80: 467-470 (2013).

[82] C. Cagnin, A. Havas, O. Saritas. "Future-oriented technology analysis, its potential to address disruptive transformations”, Technol.Forecast.Soc.Chang 80: 379-385 (2013).

[83] R. Rohrbeck, H.G. Gemünden. "Corporate foresight: Its three roles in enhancing the innovation capacity of a firm”, Technol.Forecast.Soc.Chang 78: 231-243 (2011).

[84] O. Da Costa, P. Warnke, C. Cagnin, F. Scapolo. "The impact of foresight on policy-maing: insights from the FORLEARN mutual learning process”, Technol. Anal. Strateg. Manage. 20(3): 369-387 (2008).

[85] A.B. Moniz. "Scenario-Building Methods as a Tool for Policy Analysis", in: C. Cagnin, M. Keenan, R. Johnson, F. Scapolo, R. Barre (EDS.), Future-oriented technology Analysis: Strategic Intelligence for an Innovative Economy Springer Verlag, Berlin and Heidelberg, (2008) 185-209

[86] M. V.D. Steen and M.V. “Twist, Beyond use: Evaluating foresight that fits”, Futures 44 (2012), 475-486

[87] C. Pohl. "From Transdisciplinarity to Transdisciplinary Research", Transdisciplinary Journal of Engineering \& Science, 1(1): 74-83 (2010).

[88] J. Ratcliffe. "Challenges for corporate foresight. Towards strategic prospective through scenario thinking”, Conference paper $7^{\text {th }}$ Annual International Conference Foresight Management in Corporations and Public Organisations new Vision for Sustainability, Helsinki, Finland, $10^{\text {th }}$ June (2005) $1-21$

[89] G. Klein. “Corporate foresight - a field report”, Int.J. foresight and Inn. Pol. 8(4): 354-364 (2012).

[90] K. Cuhls, R. Johnston. “Corporate Foresight”, in: C. Cagnin, M. Keenan, R. Johnson, F. Scapolo, R. Barre (EDS.), Future-oriented technology Analysis: Strategic Intelligence for an Innovative Economy Springer Verlag, Berlin and Heidelberg, (2008) 103-114

[91] D. Pollard, S. Hotho. "Crisis, Scenarios and the strategic management process”, Manage. Dec. 44(6) (2006) 721-736

[92] M.P.E. Cunha, P.Palma, N.G. da Costa. "Fear of foresight: knowledge and ignorance in organisational foresight”, Futures 38 (2006) 942-955

[93] H.A.Von Der Gracht, C.R. Vennemann and I. Darkow. ”Corporate foresight and innovation management, A portfolio-approach in evaluating organisational development", Futures, 42(4) (2010) 380393.

[94] S.D. Green, C. Kao and G.D. Larsen. "Contextualist Research, Iterating between Methods While Following an Empirically Grounded Approach”, Journal of Construction Engineering and ManagementAsce, 136(1) (2010) 117-126.

[95] K. Haegeman, K.M.Weber, T. Könnölä. "Preparing for grand challenges: the role of future-oriented technology analysis in anticipating and shaping structural and systemic changes", Technol. Anal. Strateg. Manage. 24(8) (2012) 729-734

[96] R. Popper. "How are foresight methods selected", Foresight 10(6) (2008) 62-89

[97] H.A. Linstone. “Three eras of technology foresight”, Technovation 31 (2011) 69-76 
[98] P. Goodwin. “Why hindsight can damage foresight”, Int.J.Appl.Forecast 17 (2010) 5-7

[99] P.D. Andersen, L.B. Rasmussen. "The impact of national traditions and cultures on national foresight processes",

[100] P.D. Algica. "The challenge of the future and the institutionalization of interdisciplinarity, notes on Herman Kahn's legacy”, Futures 36 (2004) 67-83

[101] I. Alexander. "Introduction, Scenarios in System Development. In Scenarios, Stories, Use Cases Through the Systems Development Life-Cycle", IF Alexander and N Maiden (ed), pp. 3-24. West Sussex, England, John Wiley \& Sons, Ltd (2004).

[102] H. Kahn and A. Wiener. "The year 2000", N.Y. US, Macmillan (1967).

[103] W.B. Rouse and K.R. Boff. "Organisational Simulation", New Jersey, John Wiley \& Sons, Inc (2005).

[104] R. Bood and T. Postma. "Strategic Learning with Scenarios", European Management Journal, 15(6) (1997) 633-647.

[105] M. Fijnvandraat, H. Bouwman. "Predicting the unpredictable: dealing with risk and uncertainty in broadband roll-out", Foresight, 12(6) 2010, 3-19

[106] E. Laes ,D. Ruan , F.Maes , A.Verbruggen . ”Methodological challenges in combining quantitative and qualitative foresight methods for sustainable energy futures : the SEPIA project”. In M. Giaoutzi, and S. Bartolomeo (eds.) “ Recent developments in foresight methodologies”. New York, US, Springer ( 2013), pp. 253-274

[107] K. Kok and H.v. Delden. ”Linking narrative Storylines and Quantitative Models to Combat Desertification in the Guadalentín Watershed”. In M. Giaoutzi, and S. Bartolomeo (eds.) "Recent developments in foresight methodologies”. New York, US, Springer ( 2013), pp. 203-214

[108] E. Kemp-Benedict. “Going from Narrative to Number Indicator-Driven Scenario Quantification”. In M. Giaoutzi, and S. Bartolomeo (eds.) "Recent developments in foresight methodologies". New York, US, Springer (2013), pp. 123-132

[109] E. Terk. "Opportunities for Combining Quantitative and Qualitative Approaches in Scenario Building: The Experience of the“Estonia 2010’ Project”. In M. Giaoutzi, and S. Bartolomeo (eds.) “ Recent developments in foresight methodologies”. New York, US, Springer (2013), pp. 297-307

[110] J. Alcamo. "The SAS approach: Combining qualitative and quantitative knowledge in environmental scenarios.” In J. Alcamo (Ed.), Environmental futures: The practice of environmental scenario analysis (Developments in integrated environmental assessment, Amsterdam, Elsevier. Vol. 2 (2008), pp. 123-150. [111] A.T. Roper, S.W. Cunningham, A.L. Porter, T.W. Mason, F.A. Rossini and J. Banks. "Forecasting and Management of Technology”. New Jersey, US, John Wiley \& Sons, Inc. (2011).

[112] J.P. Martino. “Technological Forecasting for Decision Making”. New York, US, McGraw-Hill. (1983).

[113] A.L. Porter and F.A. Rossini. “Technological Forecasting”. In Encyclopedia of Systems and Control, M. Singh. Oxford, UK, Pergammon, pp. 4823-4828.

[114] H.A. Linstone. "Multiple Perspective: Concept, Applications and User Guide-lines”. System Practice. 2(3) (1989) 307-331.

[115] E. Jantsch. "Technological Forecasting in Perspective”. Paris, OECD, (1967)

[116] S. Makridakis, S. C. Wheelwright and R.J. Hyndman. "Forecasting, Methods and Applications". Third Ed., US, John Wiley \& Sons, Inc. (1998).

[117] B.C. Twiss. "Forecasting for Technologists and Engineers - A practical guide for better decisions". Herts, UK, Peter Peregrinus Ltd. (1992)

[118] G.P. Spithourakis, F. Petropoulos, K. Nikolopoulos and V. Assimakopoulos. "Amplifying the learning effects via a Forecasting and Foresight Support System”. International Journal of Forecasting. 31 (2015), 20-32 
